\title{
The Correspondence between Syntax and Semantics
}

\author{
Cherif Teimi ${ }^{1}$ \\ ${ }^{1}$ Faculty of Arts, Ibn Tofail University, Kenitra, Morocco \\ Correspondence: Cherif Teimi, Faculty of Arts, Ibn Tofail University, Kenitra, Morocco. E-mail: \\ cteimi@jazanu.edu.sa
}

$\begin{aligned} & \text { Received: February 12, } 2016 \\ & \text { Accepted: April 25, } 2016 \quad \text { Online Published: May 25, } 2016 \\ & \text { doi:10.5539/ijel.v6n3p118 }\end{aligned}$ URL: http://dx.doi.org/10.5539/ijel.v6n3p118

\begin{abstract}
The issue of Interfaces is central to linguistic studies. Modern linguistics, especially semantic studies, has given a special interest to this topic. However, up till very recently, the issue has been dealt with mainly from a syntactico-centric point of view. Throughout the development of linguistic theories, there has been a rooted idea in generative grammar that meaning is generated from syntactic structure. In fact, although we adopt the Conceptual Semantics framework, which considers meaning to be too rich and multidimensional to be encoded in purely syntactic mechanisms, we shall deal with the correspondence between syntax and semantics where these two components directly correlate with one another. In other words, we will deal with the topic from the angle where syntax bears all semantic relations.
\end{abstract}

Keywords: conceptual semantic, thematic roles, conceptual structure, syntactic structure, macroroles, agent, patient, theme

\section{Introduction}

In generative grammar including the Minimalist Program, there has been a rooted idea that the interface between syntax and semantics is a trivial one-to-one correspondence. Nonetheless, this idea is refuted in the Conceptual Semantics Framework. In this article, however, we will deal with sentences where there is a sort of total correspondence between syntactic structure and conceptual/ semantic structure. In other words, we will deal with data that prove that there are contexts where syntactic structures bear all semantic relations. This task will be carried out in terms of Thematic Roles which are considered as particular argument positions in conceptual functions (Jackendoff, 2007, p. 195). These Thematic Roles are linked to syntactic positions via Interface Rules. As Jackendoff (2007, p. 193) points out, "The level of conceptual structure is linked to linguistic structures by interface rules, rules that relate distinct levels of representation. Among the interface rules are words, which connect pieces of conceptual structure to pieces of syntactic and phonological structure. There are also interface rules that deal with phrase- and sentence-sized structures." As is clear from Jackendoff's statement, there are interfaces between conceptual structure and other linguistic components, especially syntactic structure and phonological structure. In the coming paragraphs, we will see how conceptual structures link to syntactic structures. This will be conducted, as we already stated, based on how Thematic Roles correlate with syntactic positions. We shall use data from Standard Arabic and English.

\section{Linking Thematic Roles to Syntactic Positions}

Thematic roles are special positions in the functional structure. These roles are linked to syntactic positions in that they constitute an interface between Conceptual Structure and Syntactic Structure. Based on this, we will deal with how syntactic positions relate to semantic relations. Following Van Valin (2005) and Jackendoff (2007) the subject position bears most of thematic roles. The following schema taken from Van Valin $(2005$, p. 54) clarifies this point. (1) 


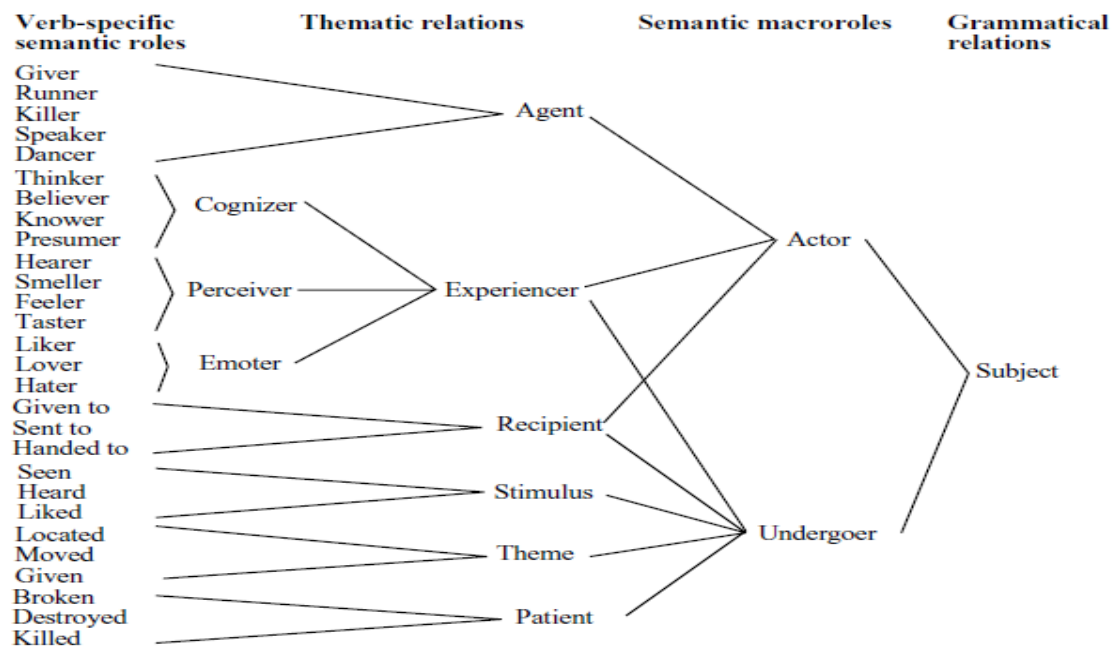

Figure 1. Continuum from verb-specific semantic roles to grammatical relations

From this schema, it seems that the majority of semantic/ thematic roles correlate with subject position. Yet, this schema does not contain all thematic roles. Source and location, for instance, which also link to subject position as we will see, are not represented here. However, Van Valin, as we notice here, produces another tier called macrorole tier since the roles Agent and Patient do not express non-action or perception verbs, reception verbs, location verbs etc. Macrorole tier is a generalized role that contains other sub-roles. Adding the macrorole tier enables us to account for most semantic relations. In (1) the roles Actor and Undergoer are the generalized roles that contain other semantic roles and subject is the syntactic position that bears all these roles. According to Van Valin (2005, pp. 129-130) "The linking between semantic and syntactic representations is governed by a very general constraint, the completeness constraint [...].

\section{Completeness constraint:}

All of the arguments explicitly specified in the semantic representation of a sentence must be realized syntactically in the sentence, and all of the referring expressions in the syntactic representation of a sentence must be linked to an argument position in a logical structure in the semantic representation of the sentence".

According to Van Valin's completeness constraint, semantic roles, which are special arguments in the conceptual structure, must be linked to syntactic positions. This is carried out by different types of relations that link a predicate with its arguments in a sentence; the predicate, a verb or other grammatical categories, has a certain number of arguments, each of which bears a distinct semantic role. This is referred to as the verb's argument structure (Van Valin, 2004, p. 23). To be organized, I shall analyze each of these thematic roles in respect to the syntactic positions they relate to or occupy. The first thematic role we consider here is the role Agent.

\subsection{Linking the Role Agent to Subject Position}

Consider the following example.

(2) John threw the ball.

\section{Syntactic Structure: Subject Object}

Conceptual Structure: Agent Theme

Here in (2) we notice that there is a one-to-one interface between the syntactic and conceptual structure. The role Agent in the conceptual structure relates to subject position in the syntactic structure and the role Theme links to object position. Relating this to the schema in (1), the role Agent is equal to the role Actor and the role Theme is equal to the role Undergoer. The standard tests that prove this analysis is the Actor and Patient tests respectively: what $X$ did was that ... and what happened to $X$ was that...Here, what John did was throw the ball and what happened to the ball was that John threw it. Hence, there is, in this example, a total correspondence between the syntactic structure and conceptual structure. The role Agent, which is an Actor in the macrorole tier, is linked to subject position and Theme, which is an Undergoer in the macrorole tier, is linked to object position. 


\subsection{Linking the Role Theme to Subject Position}

Now, we deal with the role Theme which also comes in contexts where it occupies subject position in the syntactic structure. According to Jackendoff (1972, p. 30) "depending on the main verb and the presence of other NPs, the Theme can be either subject or direct object". Take the following examples from Standard Arabic. (Note 1)

(3) Sadamat 1-sayyaaratu 1-fajarata.

Hit 3rd p Sing Femin Past the-car-NOM the-tree-ACC

Syntactic structure: Subject Direct object

Conceptual structure: Theme Patient

"The car hit the tree"

In this Arabic sentence, al sayyaaratu (the car) with the nominative case is a subject in the syntactic structure and Theme in the conceptual structure.It is a theme because it is the element/object (Note 2) that undergoes motion. And al shajarata (the tree) with the accusative case is an object in the syntactic structure and Patient in the conceptual structure. Here, Theme is an Actor in the macrorole tier and Patient is an Undergoer. Therefore, as we notice in the structure in (3), the role Theme is linked to subject position, and Patient is linked to object position. Continuing this way, we will find out that most of thematic roles can relate to subject position. Let us treat each of these thematic roles independently.

\subsection{Linking the Role Patient to Subject Position}

Consider the following examples from Arabic.

(4) a. maat-a Khaalidun

Died-3rd p Sing Masc PastKhalid-NOM

Syntactic structure: Subject

Conceptual structure: Patient

"Khalid died"

b. John got sick

Syntactic structure: Subject

Conceptual structure: Patient

The Arabic sentence in (4a) describes an event, the death of Khalid. This is expressed by the unaccusative (Note 3) verb maata (die) that does not require an object in the sentence. Khalid with the nominative case is a subject in the syntactic structure and Patient in the conceptual structure. Thus, the role Patient correlates with subject position. To put it differently, there is an interface between the syntax and semantics of the sentence in (4a) that there is a correspondence between the subject in the syntactic structure and Patient in the conceptual structure.

The same thing can be said about the English sentence in (4b). There is a correlation between the syntactic structure and conceptual structure of this sentence. The role Patient in the conceptual structure correlates to subject position in the syntactic structure. As a matter of fact, all unaccusative verbs express the role Patient in subject position. The following examples from Arabic and English prove this claim.

(5) a. mariḍa Khalidun

Got sick-3rd p Sing Masc Past Khalid-NOM

Syntactic structure: Subject

Conceptual structure: Patient

"Khalid got sick"

b. Pinhaara l-haa?itu

collapsed-3rd p Sing Masc Past the wall-NOM

Syntactic structure: Subject

Conceptual structure: Patient

"The wall collapsed" 
c. Pihtaraqa 1-taSaamu

burnt-3rd p Sing Masc Past The-food-NOM

Syntactic structure: Subject

Conceptual structure: Patient

"The food burnt"

d. taSatalat l-sayyarat-u

broke down-3rd p Sing Femin Past the car-NOM

Syntactic structure: Subject

Conceptual structure: Patient

"The car broke down"

e. d'aabat 1-shukulatatu

melted-3rd p Sing Femin Past the chocolate-NOM

Syntactic structure: Subject

Conceptual structure: Patient

"The chocolate melted"

f. tasarraba 1-maa?u

Leaked-3rd p Sing Masc Past the-water-NOM

Syntactic structure: Subject

Conceptual structure: Patient

"The water leaked out"

We can add more sentences of this kind from Arabic. Similarly, the English unaccusative verbs behave the same way. The role Patient correlates with subject position.

(6) a. The window broke.

Syntactic structure: Subject

Conceptual structure: Patient

b. The ice melted.

Syntactic structure: Subject

Conceptual structure: Patient

c. The train departed.

Syntactic structure: Subject

Conceptual structure: Patient

d. The disease spread.

Syntactic structure: Subject

Conceptual structure: Patient

e. The gas appeared.

Syntactic structure: Subject

Conceptual structure: Patient

In these sentences with unaccusative verbs, all subjects are not Agents but rather Patients in the conceptual structure. Hence, in the case of sentences with unaccusative verbs, subjects correlate with Patients. Sentences in (5) and (6) pass the test what happened to $X$ was ... and not the test what $X$ did was ...

Applying the Patient test to sentences (5a-f) and (6a-e) gives us (7a-f) and (8a-e) respectively.

(7) a. What happened to Khalid was that he got sick.

b. What happened to the wall was that it collapsed. 
c. What happened to the food was that it burnt.

d. What happened to the car was that it broke down.

e. What happened to the chocolate was that it melted.

f. What happened to the water was that it leaked out.

(8) a. What happened to the window was that it broke.

b. What happened to the ice was that it melted.

c. What happened to the train was that it departed.

d. What happened to the disease was that it spread.

e. What happened to the gas was that it appeared.

As we see here, all subjects are Patients in the conceptual structure. Sentences with unaccusative verbs do not necessitate subjects to be Agents/Actors but rather Patients. Why?

Here we go back to the issue of volition and intentionality. It seems that unaccusative verbs select Actors that are not intentionally responsible for the events that happen to them as the case in (5a) shows. There must be another entity, sometimes meta-natural entity, which causes the event. Khalid in (4a) and John in (4b), for instance, should not bring about the events of getting dead and getting sick respectively. We infer here that syntax, more specifically, case marking, does not make any distinction between the meaning of sentences with unaccusative verbs and those with unergative verbs in Arabic. Look at these two sentences from Arabic.

(9) a. daxala 1-rajulu

entered-3rd p Sing Masc Past The man-NOM

Syntactic structure: Subject

Conceptual structure: Agent

"The man entered"

b. mariḍa l-rajul-u

got sick-3rd p Sing Masc Past the man-NOM

Syntactic structure: Subject

Conceptual structure: Patient

"The man got sick"

Both (9a) and (9b) contain subjects with nominative case al rajulu (the man) but in the former the subject is an Agent in the conceptual structure, and in the latter it is a Patient. Thus, unergative verbs like enter in English and its equivalent daxala in Arabic express actions that are volitional/ intentional. They require volitional agents unlike unaccusative verbs. As defined by Van Valin, "Agents are typically animate and normally instigate the actions they perform and do so willfully and intentionally" (Van Valin, 2004, p. 24). Thus, as we notice in (9a), al rajul-u (the man) is the instigator of the action; whereas in (9b) al rajulu (the man) does not instigate the event. Therefore, what makes the role Patient correlate with subject position in (9b) and in all sentences with unaccusative verbs is the absence of volition/ and intentionality. And if the element expressed in subject position is what instigates the action, the role that will be assigned to is the role Agent, as we see in (9a). However, this should not be taken as a counterexample against the fact that there exists an interface between syntax and semantics since syntax still contains the meaning of both sentences with intransitive verbs. The only difference is that the subject position correlates with the role Patient in the cases of unaccusative verbs, meanwhile it correlates with the role Agent in the cases of unergative verbs. However, the normal and usual position for the role Patient is object position especially when a sentence contains a transitive verb such as push, break, hit etc.

\subsection{Linking the Role Patient to Object Position}

Consider the following examples.

(10) a. John pushed the car.

$\begin{array}{lll}\text { Syntactic Structure: Subject } & \text { Verb } & \text { Object } \\ \text { Conceptual Structure: Agent } & \text { ACT } & \text { Patient }\end{array}$


b. John broke the cup.

$\begin{array}{lll}\text { Syntactic Structure: Subject } & \text { Verb } & \text { Object } \\ \begin{array}{l}\text { Conceptual Structure: Agent } \\ \text { c. Mary hit John. }\end{array} & & \text { Patient } \\ \text { Syntactic Structure: Subject } & \text { Verb } & \text { Object } \\ \text { Conceptual Structure: Agent } & \text { ACT } & \text { Patient }\end{array}$

Up till now, we found out that subject position is usually linked to Agent/Actor role and the normal syntactic position that correlates with the role Patient is the object position. According to Jackendoff $(2007$, p. 202) "The macrorole tier plays an important role in linking conceptual structure to syntax. The basic idea stems from the insight that the relation between semantic roles and syntactic positions is not random. In particular, the Actor role, if present, has a strong claim on subject position (in active sentences)." This is governed by a general interface rule that is stated in Jackendoff (2007, p. 203).

\section{(11) Linking of macroroles to syntax}

a. The first macrorole (Actor if there is one, otherwise Patient/ Beneficiary) is expressed in subject position.

b. The second macrorole, if there is one, is (canonically) expressed as the postverbal NP (indirect or direct object).

c. Any remaining NP arguments in the syntax (e.g., the direct objects of enter and receive) are linked to roles in the thematic tier.

Also, another interesting observation we make here is that when the action or event is self-initiated (i.e., the Actor is volitionally responsible for it), the role that correlates to subject position is the role Agent as is shown by the example (9a). Otherwise, Patient is what links to subject position as in the case of sentences with unaccusative verbs. Thus, what makes subject position correlates with the role Patient is the absence of volition/ and intention of the entity over which the event is brought about as we saw in examples (4), (5) and (6). Therefore, the presence of intention and/ volition in the entity expressed in subject position automatically means that the role that will correlate with subject position is the role Agent, a volitional Actor.

\subsection{Other Thematic Roles that Link to Subject Position}

There are other thematic roles that can correlate with subject position. Yet, subject position is not the usual position for these roles. Here we deal with some of them (I put the concerned Thematic roles in dark scripts).

(12) a. John got a scholarship from Cambridge.

Syntactic Structure: Subject V direct object PP

Conceptual Structure: Beneficiary Receive Theme Source

b. Susan received a letter.

Syntactic Structure: Subject V direct object

Conceptual Structure: Recipient Receive Theme

c. The dean received a student at his office.

Syntactic Structure: Subject V direct object PP

Conceptual Structure: Goal RECEIVE Theme Place

d. Mary gave John a book.

Syntactic Structure: Subject V direct object indirect object

Conceptual Structure: Source ACT Beneficiary Theme

e. Morocco is a peaceful country.

Syntactic Structure: Subject V Adjective Noun

Conceptual Structure: Location BE Property Place

The role Beneficiary in (12a) correlates with subject position. John is the entity that benefits from the scholarship. However, the role Beneficiary is somewhat parallel to the role Patient. The only difference between the two is that the former is $[\mathrm{AFF}+]$ (positively affected) and the latter is [AFF-] (negatively affected) (See, for instance, Jackendoff, 2007, p. 202). The Beneficiary Test is: What X did for $Y$ was such and such; whereas The Patient 
Test is: What $X$ did to $Y$ was such and such. We consider the examples in (13) then apply the mentioned tests to them.

(13) a. Mary forced John to leave.

b. Mary enabled John to leave.

John in (13a) is Patient since the sentence in question passes the test "What $X$ did to $Y$ was such and such." Here, what Mary did to John was force him to leave, whereas John in (13b) is Beneficiary since the sentence in question passes the test "What X did for Y was such and such". Therefore, what Mary did for John was enable him to leave.

In (12b) Susan is a subject in the syntactic structure and Recipient in the conceptual structure. Susan here does nothing but receives a letter. She is not responsible for the moving of the letter. Thus, a Recipient is a sort of an Actor that is not the initiator of the main action; here, sending or carrying out a letter to Susan. In other words, Susan is not the person who causes the letter to move; there has to be another person who causes the letter to move toward Susan, the Recipient. In (12c) the dean is the Goal of the student's action which is moving or going toward the dean's office. The dean who is sitting at his office is a Goal for the student. The role Goal in (12c) correlates with subject position because the dean in the sentence is not the initiator of the main action, just as in (12b). The dean here is a Goal (a destination) of the action of moving performed by the student. Here, Goal and recipient are quite similar but they differ in that Goal refers to the endpoint of a change of location, while Recipient refers to the endpoint of a transfer of possession (Van Valin, 2004, p. 24).

In (12d) Mary in subject position is Source in conceptual structure, the source of the book given to John. The role Source here is equal to the role Agent; we can substitute Source with Agent. In fact, in many sentences, the role Agent expressed in subject position can be Source. John in the following sentence is Source since he is the origin from which the ball moves away.

(14) John threw the ball.

In (12e), there is a correlation between subject position in the syntactic structure and the role Location in conceptual structure. The function in this sentence is BE, which holds two arguments. The first is Morocco and second is the adjective phrase, peaceful country, which is a property of Morocco (modifier of Morocco) in the conceptual structure.

However, the Thematic Roles Beneficiary, Recipient, Goal, Source and Location, in (12) correlate with subject position though their normal and usual position in syntactic structure is either object position or post-object position as prepositional phrase. Look at (15).

(15) a. John gave Mary a present.

Syntactic Structure: Subject V direct Object indirect Object

Conceptual Structure: Agent ACT Beneficiary Theme

b. John sent an e-mail to Mary.

Syntactic Structure: Subject V NP PP

Conceptual Structure: Agent ACT Theme Recipient

c. John went to New York.

Syntactic Structure: Subject V PP

Conceptual Structure: Agent Go Into Goal

d. John got a scholarship from Cambridge.

Syntactic Structure: Subject V direct object PP

Conceptual Structure: Recipient Receive Theme Source

e. The theater is in the center of the city.

Syntactic Structure: Subject V PP

Conceptual Structure: Place BE Location

The examples in (15) instantiate the thematic roles that correlate with Prepositional phrases; the normal and usual positions for the roles in question. In (15a) the role Beneficiary links to direct object in syntactic structure. Direct object is the normal position for the role Beneficiary and not subject position. Agent is what correlates to 
subject position as stated in the constraint (a) in (11) above. In (15b) the role Recipient correlates with the Prepositional phrase in the syntactic structure. The Prepositional phrase is the normal syntactic position for the role Recipient since this latter requires to be expressed by a Path function, TO or INTO. Similarly, the role Goal in (15c) is linked to the Prepositional phrase since it requires a Path function, too. The role Goal is usually expressed by a Prepositional phrase in the syntactic structure that correlates with the function TO or INTO in the conceptual structure. Furthermore, the role Source in (15d) correlates with a prepositional phrase. This is the normal and usual syntactic position for the role Source which is usually expressed by a prepositional phrase in the syntactic structure and function FROM in the conceptual structure. Last but not least, the role Location also correlates with prepositional phrases and the function that holds this role is the function IN which links to prepositional phrases in the syntax.

However, subject position, as we have seen in (12), can bear all these Thematic Roles. What insight can we get from this? This gives us two insightful ideas. The first is that syntax is a more general configuration that bears all semantic/ conceptual roles (but this does not mean that syntax is what determines meaning; meaning is composed in different linguistic levels (Lexical, phonological, syntactic and semantic) and non-linguistic levels (cognitive and cultural). The second is that Subject position is the most important position in the syntactic structure that correlates with most of Thematic Roles. Here we confirm the validity of the schema in (1) taken from Van Valin (2005) which shows that subject position correlates with all thematic roles.

\section{Conclusion}

As we have seen in this article, subject position can bear most thematic roles. There are contexts where these roles correlate with subject position. However, some of these roles have a stronger claim on particular syntactic positions than others. Agent, for instance, if present, has a strong claim on subject position. In case the verb requires the action to be instigated by a volitional/ intentional actor, this actor must be an Agent that correlates with subject position in the syntactic structure. Interestingly, we discover that the absence of volition and intention of the entity expressed in subject position, as the case of sentences with unaccusative verbs show, is behind the linking of the role Patient with subject position. This is because the entity expressed in subject position is not the instigator of the event or action in question. Therefore, we take it to be Patient in the conceptual structure, the entity affected by the event. Hence, intention and volition play an important role in linking thematic roles to syntactic positions. Last but not least, we put forth general conditions that govern the linking of thematic roles with syntactic positions.

(a) Agent: If the verb in a sentence requires the action or event to be instigated by a volitional/ intentional Actor, the role Agent has a strong claim on subject position.

(b) Patient: In cases of sentences with transitive verbs, Patient normally links to direct object position. Here, Patient is affected by the action of the Agent. However, in cases of sentences with unaccusative verbs, where the entity expressed in subject position is not the instigator of the action or event, that entity is taken to be Patient.

(c) Theme: the role Theme, which is usually defined as the element that is located or undergoes change of location or possession, correlates either with subject position or direct object. As we saw in the example "the car hit the tree", the car is a subject in the syntactic structure and Theme in the conceptual structure; it cannot be considered Agent because it lacks intentionality and volition (compare the sentence with John hit Mary (intentionality again is behind determining the role that links to subject position.). Moreover, there is another syntactic position that correlates with Theme, which I take to be the normal and usual position for Theme. This position is direct object as we saw in the example "John threw the ball". The ball here is theme since it undergoes change of location.

(d) Beneficiary, which is the element that benefits from the act of giving, usually correlates with direct object. However, there are contexts where it links to subject position as the cases of sentences with reception verbs like get.

(e) Recipient, which is an endpoint of a transfer of possession, syntactically appears in subject position as in $(12 b)$ or in direct object position as in (15b).

(f) Goal is an endpoint of an Agent or Theme moving from one place to another. As in "John went to New York" and "John threw the ball into the wall". New York and wall are Goals in the conceptual structure.

(g) Source: the origin that someone or something comes from as we saw in (15d). "I came from Rabat yesterday" also contains Source role, Rabat.

(h) Location: location is the role that expresses where the action takes place (Linda is playing in the garden) or where something is located (Morocco is a peaceful country). The role Location normally correlates with 
prepositional phrase when held by the function IN and subject position when held by the function BE. Some of thematic roles co-occur interchangeably.

Admittedly, and as we have seen in this article, the interface between syntax and semantics is a sort of a one-to-one trivial correspondence. This, however, does not mean that all dimensions of meaning are derived and dominated by syntax. Syntax bears some parts of meaning. Yet, other parts of meaning are revealed in other linguistic components as exhibited by the Parallel Architecture Approach developed in Jackendoff $(1997,2002)$ and Jackendoff \& Culicover (2005) that we may deal with in the future works.

\section{References}

Chomsky, N. (1995). The Minimalist Program. Current studies in linguistics. Cambridge, MA: MIT Press.

Jackendoff, R. (1972). Semantic Interpretation in Generative Syntax. Cambridge, Massachusetts, and London, England: The MIT Press.

Jackendoff, R. (1997). The Architecture of Language Faculty. Cambridge, Massachusetts London, England: The MIT Press.

Jackendoff, R. (2002). Foundations of Language: Brain, Meaning, Grammar, Evolution. New York: Oxford University Press Inc. http://dx.doi.org/10.1093/acprof:oso/9780198270126.001.0001

Jackendoff, R. (2007). Language, Consciousness, Culture: Essays on Mental Structure. Cambridge, Massachusetts London, England: The MIT Press.

Park, K. S., \& Lakshmanan, U. (2007). The unaccusative-unergative distinction in resultatives: Evidence from Korean L2 learners of English. In A. Belikova et al. (Eds.), Proceedings of the 2nd Conference on Generative Approaches to Language Acquisition North America (GALANA) (pp. 328-338). Somerville, MA: Cascadilla Proceedings Project.

Van Valin, R. D. (2004). An Introduction to Syntax. Cambridge: Cambridge University Press.

Van Valin, R. D. (2005). Exploring the Syntax and Semantics Interface. Cambridge: Cambridge University Press. http://dx.doi.org/10.1017/CBO9780511610578

\section{Notes}

Note 1. Note that order in Standard Arabic is VSO.

Note 2. I mean the ontological category "Object" that can be replaced by a more general ontological category, Thing.

Note 3. Intransitive verbs are distinguished into two subclasses: unaccusative verbs which denote non-willful or non-volitional actions and unergative verbs which denote willed or volitional actions (for more details see Park \& Lakshmanan 2007, p. 329).

\section{Copyrights}

Copyright for this article is retained by the author(s), with first publication rights granted to the journal.

This is an open-access article distributed under the terms and conditions of the Creative Commons Attribution license (http://creativecommons.org/licenses/by/3.0/). 